\title{
Structural and tribological characterization of tungsten nitride coatings at elevated temperature
}

\author{
T. Polcar ${ }^{\text {a,b }}$, N.M.G. Parreira ${ }^{a}$, A. Cavaleiro ${ }^{a, *}$ \\ a SEG-CEMUC - Department of Mechanical Engineering, University of Coimbra, Rua Luís Reis Santos, \\ P-3030 788 Coimbra, Portugal \\ ${ }^{\mathrm{b}}$ Department of Applied Mathematics, Faculty of Transportation Sciences, Czech Technical University in Prague, \\ Na Florenci 25, Prague 1, Czech Republic
}

Received 28 March 2007; received in revised form 4 September 2007; accepted 22 October 2007

Available online 11 December 2007

\begin{abstract}
Transition metal nitrides exhibit excellent mechanical properties (hardness and Young's modulus), high melting point, good chemical stability and high electrical conductivity. However, tungsten nitrides still stand aside of the main attention. In our previous study, tungsten nitride coatings with different nitrogen content showed excellent wear resistance at room temperature. Nevertheless, many engineering applications require good tribological properties at elevated temperature. Thus, the present study is focused on the tribological behaviour (friction coefficient and wear rate) of tungsten nitride coatings at temperature up to $600{ }^{\circ} \mathrm{C}$.

The structure, hardness, friction and wear of tungsten nitride coatings with nitrogen content in the range $30-58$ at. $\%$ prepared by dc reactive magnetron sputtering were investigated. The tribological tests were performed on a pin-on-disc tribometer in terrestrial atmosphere with $\mathrm{Al}_{2} \mathrm{O}_{3}$ balls as sliding partner. The coating wear rate was negligible up to $200^{\circ} \mathrm{C}$ exhibiting a decreasing tendency; however, the wear dramatically increased at higher temperatures. The coating peeled off after the test at $600^{\circ} \mathrm{C}$, which is connected with the oxidation of the coating.

(C) 2007 Elsevier B.V. All rights reserved.
\end{abstract}

Keywords: Tungsten nitride; Sliding wear; Oxidation; Elevated temperature

\section{Introduction}

Hard coatings have proven to be an excellent solution to improve the wear resistance of mechanical components. Tungsten nitride coatings exhibiting hardness higher than $40 \mathrm{GPa}$ are therefore potential candidates for protective coatings. Surprisingly, their friction and wear properties were not tested as intensively as other transition metal nitrides, such as $\mathrm{TiN}$ or $\mathrm{CrN}$. Nevertheless, previous studies have shown that tungsten nitride coatings exhibit excellent mechanical (adhesion, hardness) and tribological (wear resistance) properties [1]. The addition of further elements such as silicon or titanium could further improve the functional properties [1,2].

Recently, a series of tungsten nitride coatings with different nitrogen content (0-55 at.\%) was prepared and analyzed [4-6]. In general, the hardness was improved with increasing nitrogen

\footnotetext{
* Corresponding author. Tel.: +351 239790 700; fax: +351 239790701

E-mail address: albano.cavaleiro@dem.uc.pt (A. Cavaleiro).
}

content, in case of $\alpha-\mathrm{W}$ and $\beta-\mathrm{W}$ structures typical of low nitrogen contents, whereas the inverse occurred for $\beta-\mathrm{W}_{2} \mathrm{~N}$ phase. Concerning the adhesion, the critical load values, as determined by scratch-testing, dropped progressively with increasing nitrogen content while an opposite behaviour was observed for the wear resistance as a consequence of the formation of a protective third-body consisting almost exclusively of tungsten oxide.

Many engineering components are subjected to elevated temperature in tribological conditions during service. High contact surface temperatures also arise due to the generation of friction heating, particularly for large sliding speeds and contact loads. Under these extreme environments, the wear resistance strongly diminishes, which may lead to the rapid failure of the coating. Thus, it starts to be a priority to know the tribological behaviour of hard coatings with temperature. In this work, sliding tests were carried out at elevated temperature to study the friction and wear properties of the tungsten nitride coatings. This study was performed on those $\mathrm{W}-\mathrm{N}$ coatings which showed previously the most promising mechanical and tribological properties at room temperature $[5,6]$. 


\section{Experimental details}

The coatings were deposited by reactive magnetron sputtering from a pure tungsten target (99.99\% purity) onto steel substrates (DIN X210CrW12) with hardness 62 HRC (about $9 \mathrm{GPa}$ ). The substrates were mirror polished to reach a roughness $\mathrm{Ra} \leq 30 \mathrm{~nm}$. The deposition parameters were as follows: target current density of $6 \mathrm{~mA} \mathrm{~cm}^{-2}$, substrate at floating potential, slow substrate rotation at $20 \mathrm{rpm}$, inter-electrode distance of $65 \mathrm{~mm}$ and no external heating with a substrate temperature lower than $350^{\circ} \mathrm{C}$. Before deposition, an ultimate vacuum pressure better than $2 \times 10^{-4} \mathrm{~Pa}$ was reached and the substrates surface was ion cleaned with an ion gun, as described elsewhere [4]. The total pressure, i.e. sum of partial pressures of argon and nitrogen, was kept constant at $0.3 \mathrm{~Pa}$, and $\mathrm{Ar} / \mathrm{N}_{2}$ partial pressure ratio was varied in the range [0.25-1.5]. Two different pumping speeds were used (100 and $2001 \mathrm{~s}^{-1}$ ), as described below in Section 3.2. The sputtering time was selected in order to obtain coatings with thickness about $3 \mu \mathrm{m}$.

A Cameca SX-50 electron probe microanalysis apparatus (EPMA) was used for determining the chemical composition of the coatings. The structure of the films was analyzed by Xray diffraction (XRD) using a Philips diffractometer with Co $\mathrm{K} \alpha$ radiation $(\lambda=0.178897 \mathrm{~nm})$ in Bragg-Brentano configuration. The hardness $(H)$ and Young's modulus $(E)$ of the coatings were evaluated by depth-sensing indentation technique using a Fischer Instruments-Fischerscope H100, with a maximum indentation load of $50 \mathrm{mN}$. The testing procedure includes a correction of the experimental results for geometrical defects of the indenter tip, the thermal drift of the equipment and the uncertainty in the initial contact, as described in detail elsewhere [7]. The Poisson ratio used for the calculation of the Young's modulus was 0.29 .

Wear testing was done using a high temperature pin-on-disc tribometer (CSEM Instruments); the sliding partner was $\mathrm{Al}_{2} \mathrm{O}_{3}$ balls with a diameter of $6 \mathrm{~mm}$ and a load of $5 \mathrm{~N}$ giving a maximum static Hertzian pressure for an elastic contact between the ball and the coating of about $1.5 \mathrm{GPa}$. The morphology of the coating surface, ball scars, wear tracks and wear debris were examined by scanning electron microscopy (SEM); the chemical analysis of the wear tracks and the wear debris was obtained by energy-dispersive $\mathrm{X}$-ray analysis (EDS). The profiles of the wear tracks were measured with a mechanical profilometer (Tencor Alpha Step 500). The wear rates of the ball and coating were calculated as the worn material volume per sliding distance and normal load. The average value of three profiles measured in each wear track was used to calculate the coating wear rate.

\section{Results and discussion}

\subsection{Selection of appropriate candidates for high temperature sliding tests}

In our recent study [6], the tribological properties of tungsten nitrides with nitrogen content $0-55$ at. $\%$ were analyzed at room temperature. In general, the coatings could be divided into two groups with different dominant wear mechanisms. The coatings with low nitrogen content (up to 15 at. \%) exhibited higher values of friction coefficient and wear rate, since their sliding properties were dominated by abrasive wear and delamination. The high nitrogen content (33-55 at.\%) leaded to a typical threebody wear with a thick layer of tungsten trioxide consisting of small round particles. The presence of the third-body protected the coating and significantly decreased the friction; the wear modes could be described as mild and polishing. The hardness and the wear rate of tungsten nitrides are shown in Fig. 1. Three chemical compositions from the later group were selected for the tribological tests at elevated temperatures. The reasons for such a selection can be summarized as follows:

- coatings with high nitrogen content exhibited lower wear;

- the high wear resistance of these coatings is caused by the formation of a third-body between the surfaces in contact and the adhered layer of tungsten trioxide. The elevated temperature should promote the formation of such layer;

- the selected compositions cover coatings with either the highest hardness or the lowest friction and wear.

\subsection{Chemical composition and structure at room temperature}

Two chemical compositions were obtained using 10 and $20 \mathrm{sccm}$ of nitrogen flow: $\mathrm{W}_{70} \mathrm{~N}_{30}$ and $\mathrm{W}_{53} \mathrm{~N}_{47}$, respectively. Since $20 \mathrm{sccm}$ was the limit of the flowmeter, the pumping speed was reduced from 200 to $100 \mathrm{~s}^{-1}$ in order to increase the nitrogen content in the coating up to 58 at.\%. It should be pointed out that the deposition process is not fully identical with the previous study $[4,5]$, since substrate rotation was applied compared to the stationary substrate position used before.

The coating $\mathrm{W}_{70} \mathrm{~N}_{30}$ clearly exhibited the f.c.c. NaCl-type $\beta$ $\mathrm{W}_{2} \mathrm{~N}$ structure with a strong ( 1111 ) orientation (Fig. 2). The shift of the $\beta-\mathrm{W}_{2} \mathrm{~N}$ peak position in relation to the ICDD database position (ICDD card nr. 25-1257) can be correlated with the high

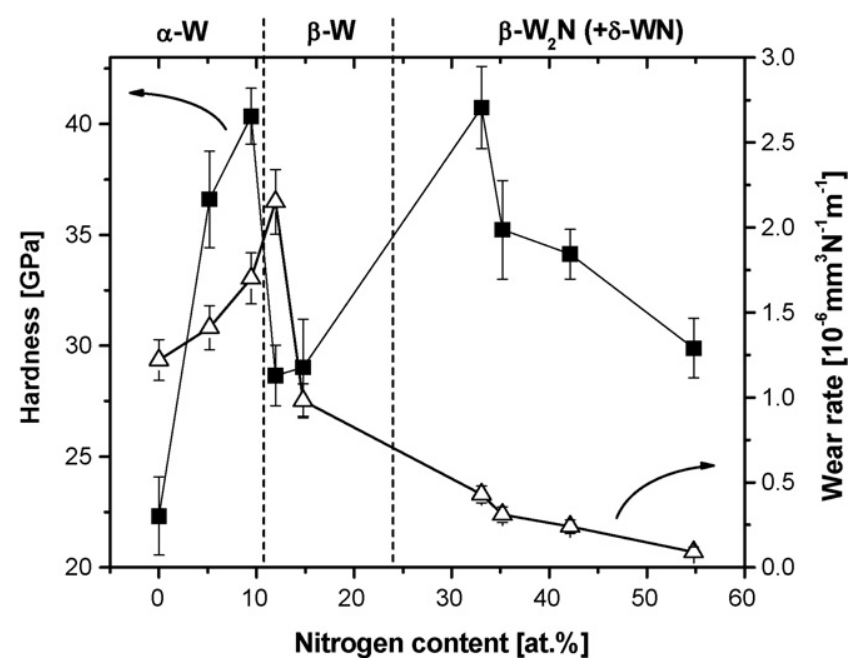

Fig. 1. Hardness and wear rate of tungsten nitride as a function of the nitrogen content [6]. 


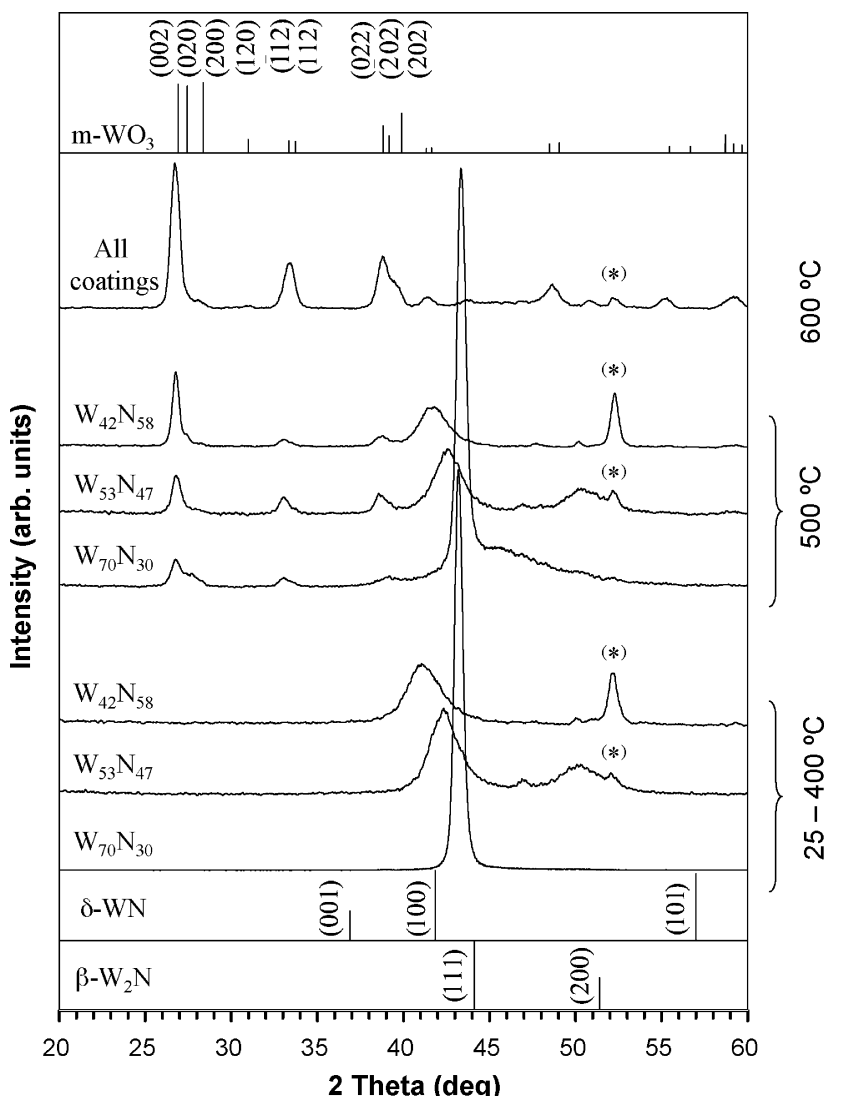

Fig. 2. XRD patterns of tungsten nitride coatings at different temperatures $(*=$ substrate $)$.

level of the residual stress, estimated as $-5 \mathrm{GPa}$, in agreement with [5].

The XRD diffractogram of $\mathrm{W}_{53} \mathrm{~N}_{47}$ showed two broad peaks, which can be attributed to (1 111$)$ and (200) reflections of the $\beta-W_{2} \mathrm{~N}$ phase. With the used sputtering deposition conditions, coatings of Zones I or T of the Thornton's model [8] are expected to be achieved, i.e. a more or less dense columnar morphology. The coating starts to grow with very small grains with $(200)$ orientation; however, further growth is accompanied with the formation of large grains with (1 1 1 1) preferential orientation [9], which matches well the experimental XRD result. As will be discussed below, the authors do not expect a significant amount of the $\delta$-WN phase in the $\mathrm{W}_{53} \mathrm{~N}_{47}$ coating, see Fig. 3 .

The XRD pattern of $\mathrm{W}_{42} \mathrm{~N}_{58}$ coating presented in Fig. 2 and in Fig. 3 shows two main diffraction peaks in the $2 \theta$ range $20-80^{\circ}$, if substrate peaks are not considered. The first peak (at $2 \theta \approx 41^{\circ}$ ) is close to the position of the ( 1111$) \beta-W_{2} \mathrm{~N}$ plan of the coatings with lower nitrogen content. However, the deconvolution of this peak shown in Fig. 3 could only be done properly considering two peaks at $2 \theta=40.95^{\circ}$ and $42.02^{\circ}$. These contributions can be attributed to the (100) plan of the $\delta$-WN phase and to the (1 111 ) reflection of the $\beta-W_{2} \mathrm{~N}$ phase (now at the same position as for $\mathrm{W}_{53} \mathrm{~N}_{47}$ ), respectively. The existence of $\delta$-WN can be further demonstrated by the detailed analysis of the broad peak in the $\left[70-80^{\circ}\right] 2 \theta$ range (Fig. 3). The deconvolution allowed to subtract the narrower peak belonging to the substrate, as can be supported by its detection at the temperature of $600^{\circ} \mathrm{C}$ (see
Fig. 2), when all the peaks corresponding to the nitride phases already disappeared due to the fully oxidation of the coating. If the lattice parameter of the cubic $\beta-\mathrm{W}_{2} \mathrm{~N}$ were calculated, considering that the $\left(\begin{array}{lll}1 & 1 & 1\end{array}\right)$ peak position $\left(2 \theta \approx 41^{\circ}\right)$ belonged to this phase then, the position of the (220) plan would be $2 \theta_{\text {cal }}=71.67^{\circ}$, clearly not matching with the experimental peak shown in Fig. 3. However, if a similar calculation were performed using (1 00 ) peak of $\delta$-WN phase, the evaluation of $a$ parameter of the hexagonal structure would allow calculating the position of the (110) plan of $\delta-\mathrm{WN}$ as $2 \theta_{\text {cal }}=74.56^{\circ}$, the exact position of the broad peak in Fig. 3 .

Comparing the XRD patterns of $\mathrm{W}_{53} \mathrm{~N}_{47}$ and $\mathrm{W}_{42} \mathrm{~N}_{58}$ coatings permits demonstrating the absence of $\delta$-WN phase in case of the coating with 47 at.\% of nitrogen. For this coating, the peak centered at $2 \theta \approx 41^{\circ}$ is well fitted considering only one function and the position of the peak close to $2 \theta \approx 73.2^{\circ}$ corresponds to the calculated (220) of $\beta-\mathrm{W}_{2} \mathrm{~N}$ phase. This structural analysis of the tungsten nitride coatings at room temperature is in agreement with other works of the same system. In general, only $\beta-\mathrm{W}_{2} \mathrm{~N}$ phase was identified in the $\mathrm{W}-\mathrm{N}$ coatings deposited by $\mathrm{DC}$ reactive magnetron sputtering with nitrogen contents up to 55 at. $\%[3,4,10]$. The presence of the hexagonal $\delta$-WN phase only occurred in coatings containing more than 55 at. $\%$ of nitrogen and vestiges of other elements, e.g. oxygen (originated from the residual atmosphere in RF reactive magnetron sputtering studies [11,12], or purposely added to the reactive atmosphere in DC reactive magnetron studies [13]), or silicon [3].

\subsection{Structural evolution with temperature}

All coating showed similar diffraction patterns from room temperature up to $400^{\circ} \mathrm{C}$. Only a small shift of the XRD peaks positions to higher diffraction angles attributed to stress relaxation was observed. The presence of small oxide peaks close to $2 \theta \approx 25^{\circ}$ revealed the superficial oxidation at $500^{\circ} \mathrm{C}$, while XRD patterns of the coatings after annealing at $600^{\circ} \mathrm{C}$ exhibited only the $\mathrm{m}-\mathrm{WO}_{3}$ structure $\left(\mathrm{WO}_{3}\right.$ monoclinic phase, ICDD card nr. 83-0950) with (0 02 ) preferential orientation. The absence

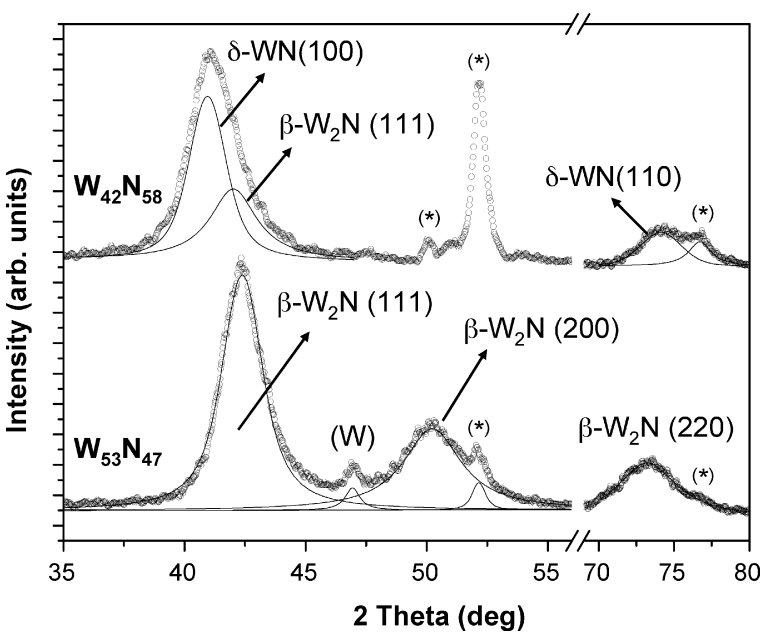

Fig. 3. XRD patterns deconvolution of as-deposited $\mathrm{W}_{53} \mathrm{~N}_{47}$ and $\mathrm{W}_{42} \mathrm{~N}_{58}$ coatings and their deconvolution $(*=$ substrate). 
of nitride phases clearly demonstrated the entire oxidation of the coating. It should be pointed out that the XRD patterns obtained after annealing at $600{ }^{\circ} \mathrm{C}$ were identical for all the tested coatings.

The indexation of the oxide phases as $\mathrm{m}-\mathrm{WO}_{3}$ could be a matter of discussion. In fact, another interpretation of the tungsten oxide structure was considered. Due to high symmetry of the XRD peak placed at $2 \theta \approx 25^{\circ}$ compared to that shown in the previous authors work dealing with the oxidation of $\mathrm{W}-\mathrm{O}$ coatings [14], the possibility of the formation of a cubic $\mathrm{WO}_{3}$ structure was analyzed in analogy to the work of Siedle et al. [15]; however, this hypothesis was abandoned due to the lack of further support.

\subsection{Hardness as a function of annealing temperature}

The variation of the hardness and the Young's modulus with the annealing temperature is shown in Fig. 4. At room temperature, $\mathrm{W}_{70} \mathrm{~N}_{30}$ was the hardest coating $(\sim 41 \mathrm{GPa})$, while the coatings with higher nitrogen content, $\mathrm{W}_{53} \mathrm{~N}_{47}$ and $\mathrm{W}_{42} \mathrm{~N}_{58}$, exhibited similar hardness values close to $30 \mathrm{GPa}$. The hardness evolution with increasing nitrogen content can be explained by the synergetic effect of two main factors: decrease of compressive stress and changes in the structure.
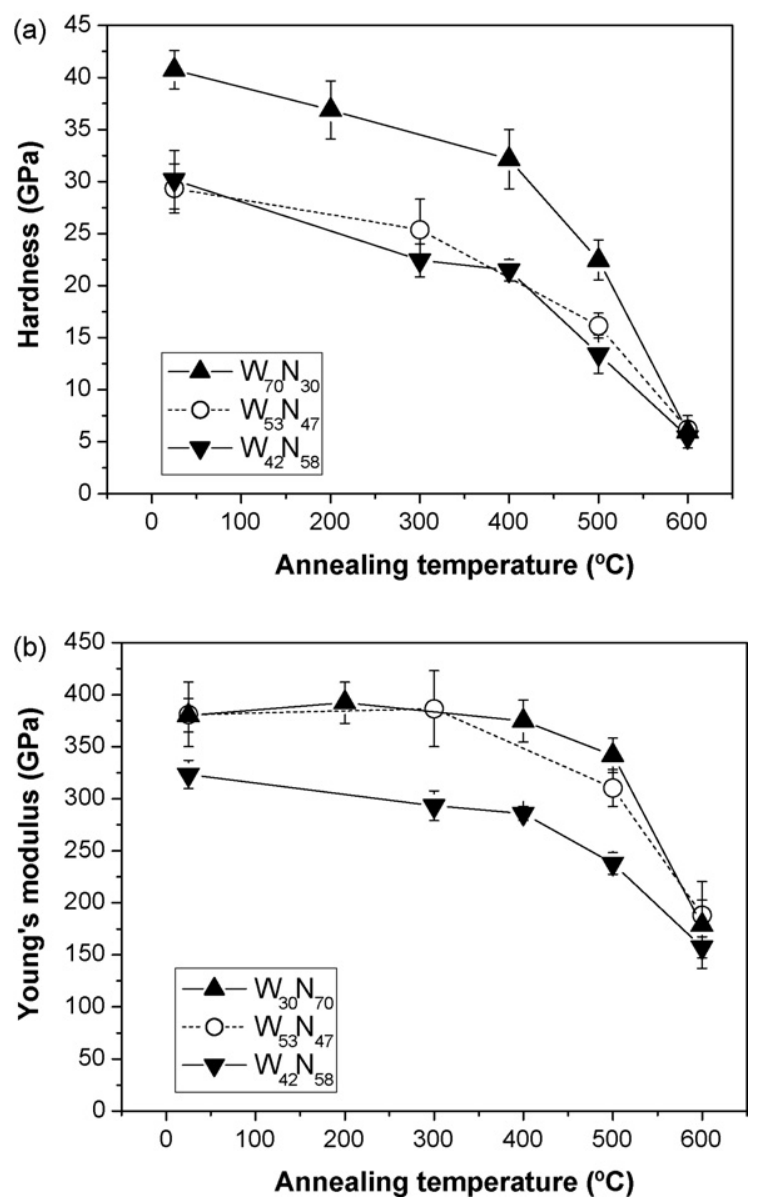

Fig. 4. Hardness (a) and Young's modulus (b) of annealed tungsten nitride coatings.

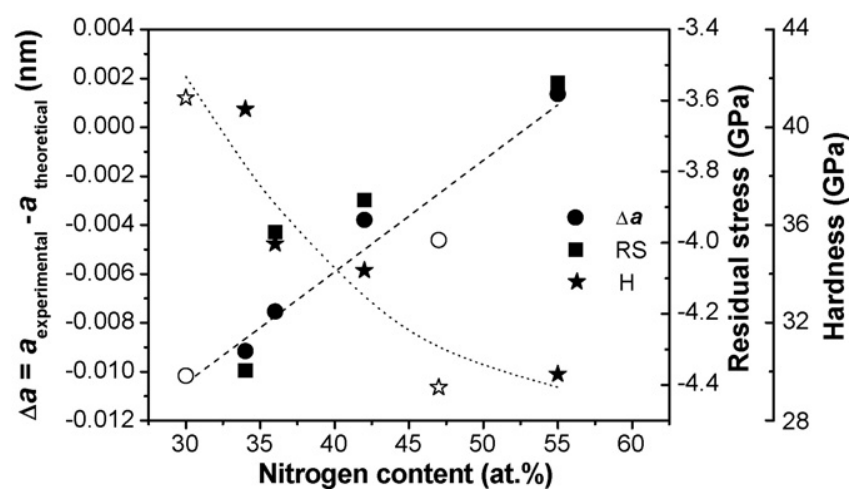

Fig. 5. Correlation between the lattice parameter, residual stress and hardness of the W-N coatings. Close symbols correspond to the previous studies [4,5] and open symbols to the coatings analyzed in this work. The lines are guides to the eye.

In the previous work [5], the residual stress measured by the deflection method was correlated with the corresponding shifts of XRD peaks; therefore, the residual stress can be estimated in the recent work from the tungsten nitride peak positions.

Fig. 5 shows the correlation between the variation in the lattice parameter, the residual stress and the hardness values presented in a previous work (filled symbols) [4,5] for the coatings with the $\beta-\mathrm{W}_{2} \mathrm{~N}$ phase. In order to eliminate the influence of the $\mathrm{N}$ content on the lattice parameter of the $\beta-\mathrm{W}_{2} \mathrm{~N}$ phase, it should be remarked that $\Delta a$ was calculated by subtracting from the experimental $a$ value (determined from the XRD peak position) the "theoretical" one. This "theoretical" value was evaluated taking into account the ICDD value indicated for the stoichiometric composition of $\mathrm{W}_{2} \mathrm{~N}$ and its linear progressive increase resulting of the occupation of the unoccupied octahedral interstitials of the f.c.c. $\mathrm{NaCl}$ type structure of $\beta-\mathrm{W}_{2} \mathrm{~N}$ by nitrogen. As can be concluded from Fig. 2, $\Delta a$ points of the films studied in present work match quite well the trends shown in Fig. 5 (see open symbols), explaining the hardness decrease between $\mathrm{W}_{70} \mathrm{~N}_{30}$ and $\mathrm{W}_{53} \mathrm{~N}_{47}$ coatings. The higher $\mathrm{N}$ content film, $\mathrm{W}_{42} \mathrm{~N}_{58}$, led to the occurrence of the hexagonal $\delta-W N$ phase, structural change that did not induce any significant change in the hardness of the as-deposited films (see Fig. 4).

The increase of the annealing temperature caused a slow decrease of the hardness. The difference of the hardness between the room temperature and $400{ }^{\circ} \mathrm{C}$ was approximately $8 \mathrm{GPa}$ in all the three coatings. Since neither variation of structure nor oxidation was observed, the hardness decrease with temperature can be attributed to a decrease of the compressive stress, which is closely related to the stress relaxation and decrease of defect density induced by the heating. These effects complemented with the oxidation starting, justify the further drop in the hardness observed at $500{ }^{\circ} \mathrm{C}$. As shown in previous section, the coatings were fully oxidized at $600^{\circ} \mathrm{C}$. As a consequence, the hardness is constant for all coatings, $6 \mathrm{GPa}$, value typical for tungsten trioxide [16].

The evolution of the Young's modulus $(E)$ for tungsten nitride coatings as a function of the annealing temperature is shown in Fig. 4b). The coatings $\mathrm{W}_{70} \mathrm{~N}_{30}$ and $\mathrm{W}_{53} \mathrm{~N}_{47}$ exhibited similar $E$ values up to $400{ }^{\circ} \mathrm{C}$, close to $380 \mathrm{GPa}$. At $500^{\circ} \mathrm{C}$, the Young's 
modulus slightly decreased to 310 and $340 \mathrm{GPa}$, respectively, and at $600{ }^{\circ} \mathrm{C}$ dropped down to $180 \mathrm{GPa}$, again a value corresponding to $\mathrm{WO}_{3}$ [16]. The Young's modulus of the coating with the highest nitrogen content, $\mathrm{W}_{42} \mathrm{~N}_{58}$, was lower than that of the other coatings. In all cases, the values obtained at room temperature are comparable with those of previous work [6].

To understand the difference in $E$ among the different coatings, the origin of the Young's modulus has to be considered. Unlike hardness, the Young's is an intrinsic property of the material depending mainly on the bonding energy between the atoms [17]. Bonding energy is related to the bonding type and the inter-atomic distance. According to the structural analysis, the coatings $\mathrm{W}_{70} \mathrm{~N}_{30}$ and $\mathrm{W}_{53} \mathrm{~N}_{47}$ showed the same phase, cubic $\beta-W_{2} N$, while the hexagonal $\delta-W N$ phase was dominant in the $\mathrm{W}_{42} \mathrm{~N}_{58}$ coating. The distance between the first neighbours (i.e. distance between tungsten and nitrogen) is lower for $\beta-\mathrm{W}_{2} \mathrm{~N}$ structure $(0.2063 \mathrm{~nm})$ than for $\delta-W N$ structure $(0.2399 \mathrm{~nm})$. Therefore, the weaker bonding in the hexagonal structure leads to a lower $E$ value. Since the structure is stable up to $400^{\circ} \mathrm{C}$, no variation in $E$ value was observed. The decrease of $E$ at $500{ }^{\circ} \mathrm{C}$ is a result of the surface oxidation and the lowest value of $E\left(E=180 \mathrm{GPa}\right.$, measured on samples annealed at $\left.600{ }^{\circ} \mathrm{C}\right)$ is attributed to the tungsten oxide layer (the value is typical of $\left.\mathrm{WO}_{3}[16]\right)$.

\subsection{Friction and wear}

The average friction coefficient and the wear rate as a function of the testing temperature of the coatings are presented in Fig. 6. Both the friction and wear exhibited similar trends for all the coatings. The friction increased from the lowest level $[0.25-0.44]$ at room temperature to a maximum in the temperature range from 200 to $300{ }^{\circ} \mathrm{C}$. A further rise in temperature was followed by a small decrease of the friction. Considering the error of the measurement, the friction value was almost identical at 300 and $400{ }^{\circ} \mathrm{C}$ for all nitrogen contents, while the lowest friction was exhibited by $\mathrm{W}_{42} \mathrm{~N}_{58}$ coating at temperatures up to $200{ }^{\circ} \mathrm{C}$ and by $\mathrm{W}_{70} \mathrm{~N}_{30}$ coating at the temperature of $500^{\circ} \mathrm{C}$.

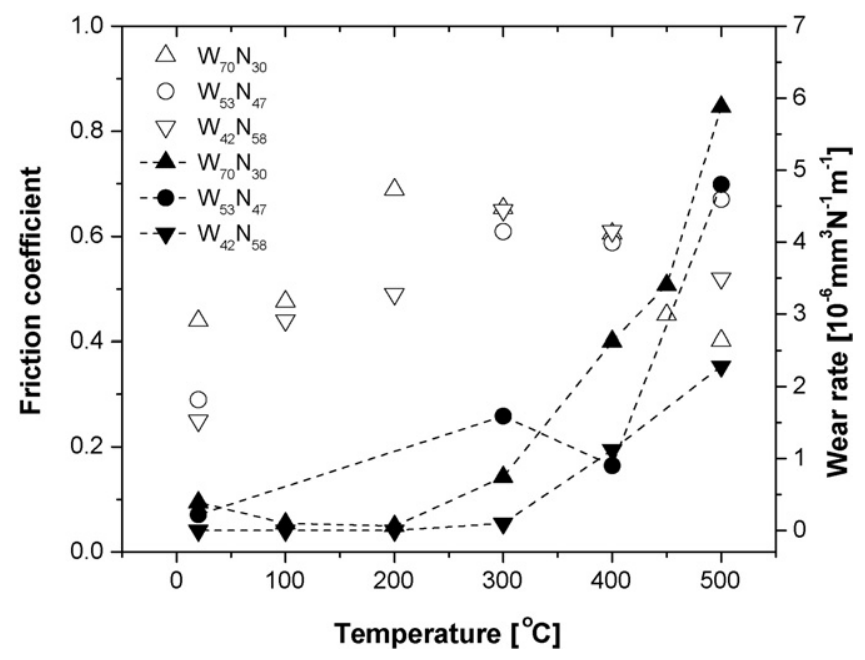

Fig. 6. The friction coefficient (open symbols) and the wear rate (close symbols) of the tungsten nitride coatings as a function of temperature.
The worn volume was almost not measurable up to $200{ }^{\circ} \mathrm{C}$ and then increased for higher temperatures. Fig. 6 clearly shows that the wear resistance at elevated temperature increased with the nitrogen content in the coatings. All coatings tested at $600{ }^{\circ} \mathrm{C}$ were worn out after the test; thus, the friction and wear data are not presented.

\subsection{Wear track analysis}

The wear tracks produced at room temperature showed a strong layer of tungsten oxide adhered on their borders; only on the central groove, direct contact between the ball and the tungsten nitride took place. This result is identical to that achieved in a previous study [6]. The adhered layer on the side started to disappear with increasing temperature and vanished at $300{ }^{\circ} \mathrm{C}$. The central part of the wear tracks, uncovered at room temperature, became covered by isolated isles of tungsten oxide at $200^{\circ} \mathrm{C}$. At $300{ }^{\circ} \mathrm{C}$, the isles started to join forming long straps. The wear tracks produced on different tungsten nitrides were very similar in the range of $20-200{ }^{\circ} \mathrm{C}$, while significant differences were observed at higher temperatures.

Fig. 7a shows a detail of the central part of the wear track produced on the coating $\mathrm{W}_{70} \mathrm{~N}_{30}$ when sliding at $300^{\circ} \mathrm{C}$. Small lateral cracks originating from the centre of the wear track can clearly be observed below the adhered tungsten oxide layer (see the arrow pointing a typical crack). The cracks occurred in the entire wear track at $500{ }^{\circ} \mathrm{C}$, as shown in Fig. $7 \mathrm{~b}$, and the iron signal detected by EDS revealed the local destruction of the coating. However, the cracks are very narrow and thus "hidden" to the mechanical profilometer. Consequently, the real value of the wear rate for $500{ }^{\circ} \mathrm{C}$ should be slightly higher compared to the values shown in Fig. 6. Surprisingly, the profilometer revealed the presence of high "walls" on the sides of the wear track, which were identified as tungsten nitride (Fig. 7b).

The wear tracks of $\mathrm{W}_{53} \mathrm{~N}_{47}$ and $\mathrm{W}_{42} \mathrm{~N}_{58}$ coatings were almost identical in all temperature range. At 300 and $400{ }^{\circ} \mathrm{C}$, the first damages appeared in the wear tracks, as shown in Fig. 8a. The partial destruction of the coating always occurred under the adhered tungsten oxide layer. It should be pointed out that only three or four similar local defects were found along the entire wear track. Further rise in the temperature to $500{ }^{\circ} \mathrm{C}$ brought a radical change, since the adhesive tungsten oxide vanished and long straps showing a severe damage were observed inside the otherwise smooth wear track Fig. 8b.

\section{Discussion}

The structural and hardness analysis shows that the evolution of the wear rate with increasing the temperature cannot be connected exclusively with either the oxidation or the considerable softening of the coating. The increase of the wear rate in range $300-400{ }^{\circ} \mathrm{C}$ for $\mathrm{W}_{70} \mathrm{~N}_{30}$ is a typical example of such behaviour, since both hardness and structure are almost identical in this temperature range. The identification of the tungsten nitride wear mechanisms at elevated temperature is a very difficult task. The only in situ measured parameter is the friction coefficient, which 
(a)
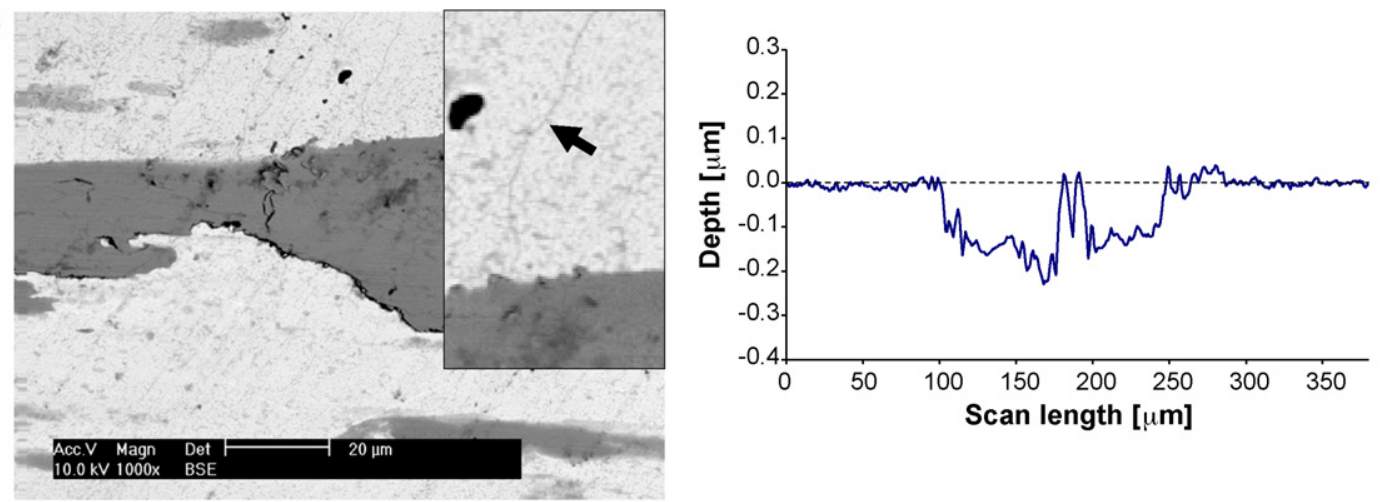

(b)
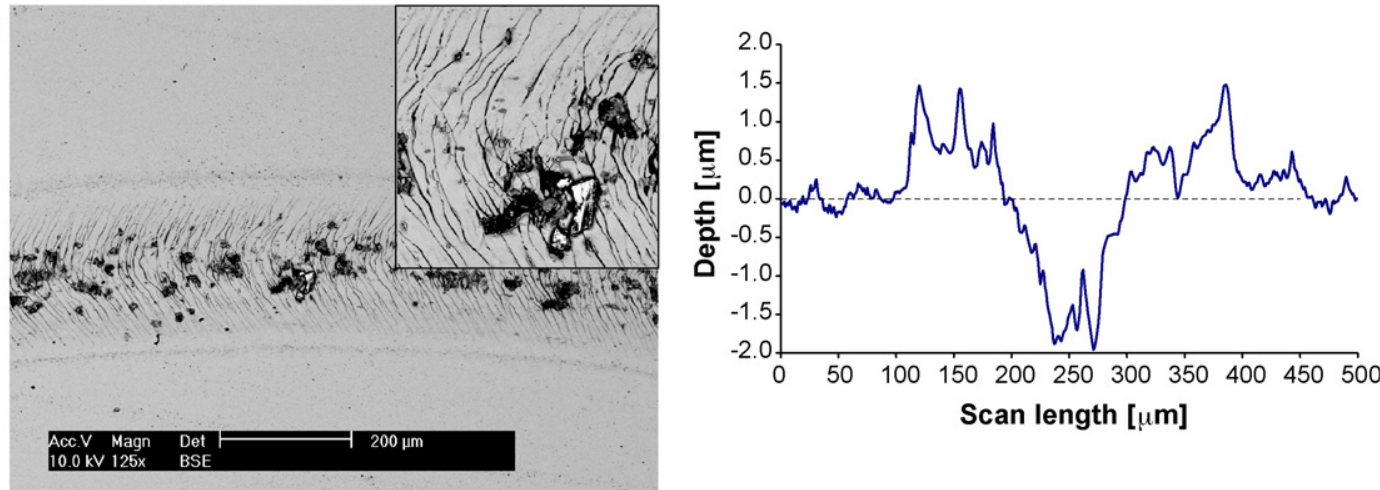

Fig. 7. SEM micrographs in BSE mode of the wear tracks and corresponding profiles of $\mathrm{W}_{70} \mathrm{~N}_{30}$ coating; (a) $300^{\circ} \mathrm{C}$; (b) $500^{\circ} \mathrm{C}$. The frame in the upper right shows detail.

(a)

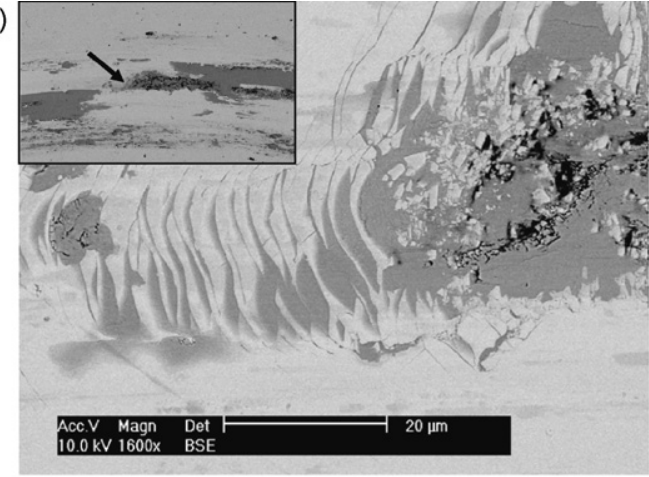

(b)

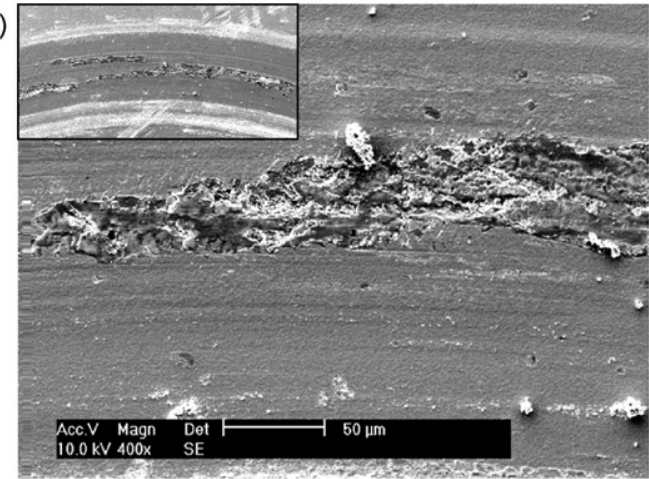

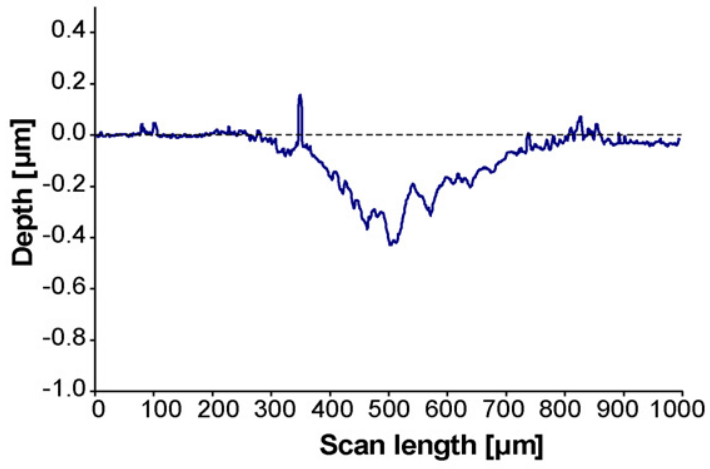

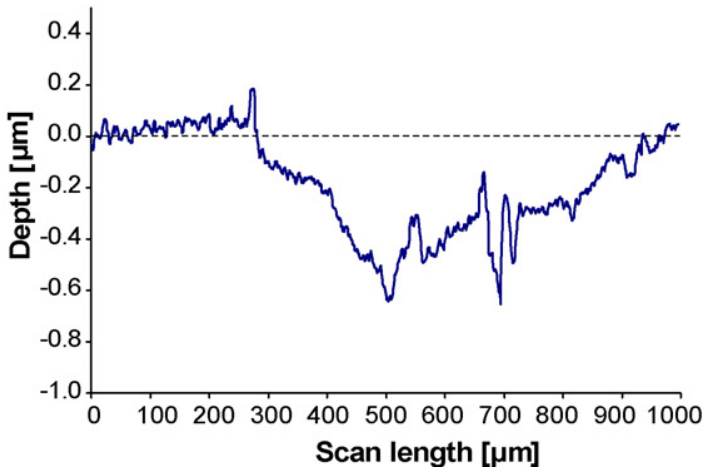

Fig. 8. SEM micrographs of the damaged part in the centre of the wear tracks of the coating $\mathrm{W}_{42} \mathrm{~N}_{58} ;$ (a) $300^{\circ} \mathrm{C}$; (b) $500^{\circ} \mathrm{C}$. The frame in the upper left shows the overall view of the wear track with the corresponding profiles shown in the right side of the figure. 
is directly dependent on the wear process and, obviously, cannot be used for the wear analysis. The evolution of the wear rate with the number of laps, i.e. the actual wear track profile, could not be measured in situ, since the maximum penetration depth is very low (usually less than $300 \mathrm{~nm}$ ), and precise profilometer cannot be applied due to the high temperature. To measure, after testing, the profile of the wear tracks produced under the same conditions with an increasing number of laps is practically impossible, since it would require an almost unlimited set of samples. The actual hardness values at elevated temperatures are unknown and can only be estimated; moreover, the surface oxidation originating either from sliding or elevated temperature decreases the hardness significantly, since the hardness of pure tungsten oxides coatings is about 6-7 GPa [16]. Therefore, the discussion about the possible wear mechanisms at elevated temperature is in many points speculative.

The observation of the wear track showed the moving of the position of the adhered oxide layer with increasing temperature. The thick layer localised in the wear track sides at room temperature disappeared and a thin layer of tungsten oxide was formed in the centre of the wear tracks at $300{ }^{\circ} \mathrm{C}$. Moreover, the first cracks appeared in all coatings at this temperature and they were always located in the zone with oxide layer. Based on the results presented above, the following model for the wear was adopted:

(I) Room temperature:

The sliding process causes oxidation of the asperities in the contact. However, the oxidation is limited to the surface of the asperity, since the energy is dissipated very quickly (flash temperature can reach hundreds of ${ }^{\circ} \mathrm{C}$, but it last less than a few milliseconds [18]). The oxidised asperity significantly expands due to the difference in the specific volume of the nitride and the oxide of tungsten $\left(\mathrm{WO}_{3}\right.$ is 2.25 times less dense than tungsten nitride, $\rho_{\mathrm{WO}_{3}}=7.2 \mathrm{~g} \mathrm{~cm}^{-3}$ and $\rho_{\mathrm{WN}}=16.2 \mathrm{~g} \mathrm{~cm}^{-3}$ [6]). Furthermore, this modified material is much softer than the bulk coating being easily worn out and producing wear debris consisting of fine tungsten oxide particles, which adhere on the sides of the wear track forming a protective layer. The direct contact between the coating and the ball occurs only in the central groove (for more details see [6]).

(II) $300-400{ }^{\circ} \mathrm{C}$ :

The wear debris does not adhere anymore on the sides of the wear track and it is driven away. Compared to room temperature, the contact area decreases and, consequently, the contact pressure increases. The frictional energy together with the elevated temperature is sufficient to oxidise the coating, a few nanometers in-depth. The oxidised asperities can expand freely, whereas the area for expansion of the oxidised surface is limited. The oxidised surface rises up and will be more likely in contact with the ball surface during the following laps than the nonoxidised surface and, thus, will undergo a higher contact pressure. Moreover, the surface oxidation produces high internal stresses in the coating due to the referred different density of the tungsten nitrides and oxides, which leads, in combination with the stresses induced by the sliding, to the crack formation.

(III) $500{ }^{\circ} \mathrm{C}$ :

At this temperature the coating surface oxidises spontaneously as revealed by XRD and optical observation (the coatings start to change the colour at approx. $450{ }^{\circ} \mathrm{C}$ ). The formation of tungsten oxide in the cracks causes additional stresses giving rise to their propagation and making possible that, eventually, small chipping occurs leaving the substrate uncovered.

The evolution of the friction supports the proposed model. The initial value is the lowest, since the contact is represented mainly by the adhered tungsten oxide. As the adhered layer disappears with increasing temperature, the friction rises, as it is observed. The friction stabilises in the range $300-400{ }^{\circ} \mathrm{C}$, since there is no significant change observed in the wear tracks of the individual coatings. The value of the friction coefficient measured at $500^{\circ} \mathrm{C}$ cannot be strictly considered as representing the tungsten nitride (or oxide), since the coatings are partially worn out. However, when the substrate without coating was tested with $\mathrm{Al}_{2} \mathrm{O}_{3}$ ball at $500{ }^{\circ} \mathrm{C}$, the friction coefficient was close to 0.5 . Therefore, no rapid change of the friction coefficient due to the coating failure could be expected.

\section{Conclusions}

Three tungsten nitride coatings with 30,47 and 58 at.\% of nitrogen were deposited by reactive magnetron sputtering. All coatings exhibited the cubic $\beta-\mathrm{W}_{2} \mathrm{~N}$ phase; however, the hexagonal $\delta$-WN phase also appeared and became dominant when the nitrogen content was 58 at.\%. The increasing temperature did not affect significantly the structure up to $400^{\circ} \mathrm{C}$. At $500^{\circ} \mathrm{C}$, the presence of weak oxide peaks revealed a surface oxidation and a further increase of the temperature led to the entire oxidation of the tungsten nitride coating. The hardness measured after annealing slightly decreased with temperature and dropped to $6 \mathrm{GPa}$ for $600^{\circ} \mathrm{C}$, a value typical for tungsten trioxide. The tribological performance of the coatings is excellent up to $300{ }^{\circ} \mathrm{C}$ with no measurable wear. Further increase in the temperature dramatically changed the wear mechanisms causing a severe coating damage in the centre of the wear track. The entire oxidation of the coating at $600^{\circ} \mathrm{C}$ is detrimental for the wear resistance.

\section{Acknowledgements}

This work was supported by the European Union through the NMP3-CT-2003-505948 project "HARDECOAT" and by the "Fundação para a Ciência e Tecnologia" of Portugal through the POCI/V.5/A0034/2005 project and the PhD Scholarship SFRH/BD/16528/2004 attributed to the author Parreira.

\section{References}

[1] J. Castanho, A. Cavaleiro, M.T. Vieira, Vacuum 45 (1994) 1051. 
[2] A. Cavaleiro, B. Trindade, M.T. Vieira, Surf. Coat. Technol. 174/175 (2003) 68.

[3] C. Louro, A. Cavaleiro, Surf. Coat. Technol. 116/119 (1999) 74.

[4] N.M.G. Parreira, N.J.M. Carvalho, A. Cavaleiro, Mater. Sci. Forum $514 / 516$ (2006) 825.

[5] N.M.G. Parreira, N.J.M. Carvalho, F. Vaz, A. Cavaleiro, Surf. Coat. Technol. 200 (2006) 6511.

[6] T. Polcar, N.M.G. Parreira, A. Cavaleiro, Wear 262 (2007) 655.

[7] J.M. Antunes, A. Cavaleiro, L.F. Menezes, M.I. Simões, J.V. Fernandes, Surf. Coat. Technol. 149 (2002) 27.

[8] J.A. Thornton, Ann. Rev. Mater. Sci. 7 (1977) 239.

[9] I. Petrov, P.B. Barna, L. Hultman, J.E. Greene, J. Vac. Sci. Technol. A 21 (2003) S117.

[10] Y.G. Shen, Y.W. Mai, D.R. McKenzie, Q.C. Zhang, W.D. McFall, W.E. McBride, J. Appl. Phys. 88 (2000) 1380.
[11] K. Affolter, H. Kattelus, M.-A. Nicolet, Proc. Symp. Mat. Res. Soc. 47 (1985) 167.

[12] P.-C. Jiang, J.S. Chen, Y.K. Lin, J. Vac. Sci. Technol. A 21/3 (2003) 616.

[13] N.M.G. Parreira, T. Polcar, N. Martin, O. Banakh, A. Cavaleiro, Plasma Process. Polym. 4 (2007) S69.

[14] N.M.G. Parreira, T. Polcar, A. Cavaleiro, Surf. Coat. Technol. 2001 (2007) 7076.

[15] A.R. Siedle, T.E. Wood, M.L. Brostrom, D.C. Koskenmaki, B. Montez, E. Oldfied, J. Am. Chem. Soc. 111 (1989) 1665.

[16] N.M.G. Parreira, N.J.M. Carvalho, A. Cavaleiro, Thin Solid Films 510 (2006) 191.

[17] S. Veprek, A.S. Argon, J. Vac. Sci. Technol. B 20 (2) (2002) 650.

[18] F.P. Bowden, D. Tabor, The Friction Lubrication of Solids. Part I, Clarendon Press, Oxford, 1954. 